\title{
An Analytical Study on Problems and Policies of Solid Waste Management in India -Special Reference to Bangalore City
}

\author{
Dr. G.1.Parvathamma, \\ Associate professor\&co-ordinatar, Department of EconomicsBangalore UniversityP.G.Centre, Kolar,
}

\begin{abstract}
One of the most pressing environmental issues facing the world today is the issue of waste management and disposal. This problem crosses all international borders and touches the lives of all the people of the world. Solid waste in most cities of developing countries is a serious threat to urban environment. Poor solid waste management is a threat to public health and causes a range of external costs. However, solid waste management in the developing countries has received lesser attention from policymakers and researchers than the other environmental problems, such as air and water pollution. Waste management encompasses everything from collection and handling to disposal by incineration, landfill and other methods, and recycling. Also included are the serious associated implications for the health of people and the environment. As waste producing activities proceed and intensify, the world community will be faced with hard choices on how to best manage and dispose of wastes. These decisions should be based on hard science and sound management practices. However, there are geopolitical dimensions to be found in the decision-making process of waste management and disposal. The purpose of this study has been to determine how geopolitical factors affect waste management on global and local scales. Specifically, this investigation has been guided by looking at how social and economic factors affecting the waste management. The Importance has been placed on Municipal solid waste generation quantity in Indian cities and its effects on environment and public health. Population growth and its impact on municipal waste. Finally, concludes that the problem of solid waste needs some holistic approaches such as reuse of solid waste to produce energy and biomennures.
\end{abstract}

Key Words: MSW, external costs, Central Pollution Control Board

\section{Introduction;}

India is the second largest nation in the world, with a population of 1.21 billion, accounting for nearly $18 \%$ of world's human population, but it does not have enough resources or adequate systems in place to treat its solid wastes. Its urban population grew at a rate of $31.8 \%$ during the last decade to 377 million, which is greater than the entire population of US, the third largest country in the world according to population). India is facing a sharp contrast between its increasing urban population and available services and resources. Solid waste management (SWM) is one such service where India has an enormous gap to fill. Proper municipal solid waste (MSW) disposal systems to address the burgeoning amount of wastes are absent. The current SWM services are inefficient, incur heavy expenditure and are so low as to be a potential threat to the public health and environmental quality. Improper solid waste management deteriorates public health, causes environmental pollution, accelerates natural resources degradation, causes climate change and greatly impacts the quality of life of citizens

Solid waste is the unwanted or useless solid materials generated from combined residential, industrial and commercial activities in a given area. It may be categorized according to its origin (domestic, industrial, commercial, construction or institutional); according to its contents (organic material, glass, metal, plastic paper etc); or according to hazard potential (toxic, non-toxin, flammable, radioactive, infectious etc). Management of solid waste reduces or eliminates adverse impacts on the environment and human health and supports economic development and improved quality of life. A number of processes are involved in effectively managing waste for a municipality. These include monitoring, collection, transport, processing, recycling and disposal.

The composition of urban MSW in India is $51 \%$ organics, $17.5 \%$ recyclables (paper, plastic, metal, and glass) and $31 \%$ of inert. The moisture content of urban MSW is $47 \%$ and the average calorific value is $7.3 \mathrm{MJ} / \mathrm{kg}(1745 \mathrm{kcal} / \mathrm{kg})$. The composition of MSW in the North, East, South and Western regions of the country varied between $50-57 \%$ of organics, $16-19 \%$ of recyclables, $28-31 \%$ of inerts and $45-51 \%$ of moisture (Table 6). The calorific value of the waste varied between $6.8-9.8 \mathrm{MJ} / \mathrm{kg}(1,620-2,340 \mathrm{kcal} / \mathrm{kg}$ 


\section{Types Of Solid Waste}

Solid waste can be classified into different types depending on their source:

a) Household waste is generally classified as municipal waste,

b) Industrial waste as hazardous waste, and

c) Biomedical waste or hospital waste as infectious waste.

\section{Municipal Solid Waste}

Municipal solid waste consists of household waste, construction and demolition debris, sanitation residue, and waste from streets. This garbage is generated mainly from residential and commercial complexes. With rising urbanization and change in lifestyle and food habits, the amount of municipal solid waste has been increasing rapidly and its composition changing. In 1947 cities and towns in India generated an estimated 6 million tonnes of solid waste, in 1997 it was about 48 million tones. More than $25 \%$ of the municipal solid waste is not collected at all; $70 \%$ of the Indian cities lack adequate capacity to transport it and there are no sanitary landfills to dispose of the waste. The existing landfills are neither well equipped nor well managed and are not lined properly to protect against contamination of soil and groundwater.

Over the last few years, the consumer market has grown rapidly leading to products being packed in cans, aluminum foils, plastics, and other such non-biodegradable items that cause incalculable harm to the environment. In India, some municipal areas have banned the use of plastics and they seem to have achieved success. For example, today one will not see a single piece of plastic in the entire district of Ladakh where the local authorities imposed a ban on plastics in 1998. Other states should follow the example of this region and ban the use of items that cause harm to the environment. One positive note is that in many large cities, shops have begun packing items in reusable or biodegradable bags.

\section{Garbage: The Four Broad Categories}

Organic waste: kitchen waste, vegetables, flowers, leaves, fruits.

Toxic waste: old medicines, paints, chemicals, bulbs, spray cans, fertilizer and pesticide containers, batteries, shoe polish.

Recyclable: paper, glass, metals, plastics.

Soiled: hospital waste such as cloth soiled with blood and other body fluids

Certain biodegradable items can also be composted and reused. In fact proper handling of the biodegradable waste will considerably lessen the burden of solid waste that each city has to tackle.

There are different categories of waste generated, each take their own time to degenerate as illustrated in the table 1 below.

Table-1, The type of litter generate and the approximate time it takes to degenerate

\begin{tabular}{|l|l|}
\hline Type of litter & Approximate time it takes to degenerate the litter \\
\hline $\begin{array}{l}\text { Organic waste such as vegetable and fruit peels, leftover } \\
\text { foodstuff, etc. }\end{array}$ & a week or two. \\
\hline Paper & $10-30$ days \\
\hline Cotton cloth & $2-5$ months \\
\hline Wood & $10-15$ years \\
\hline Woolen items & 1 year \\
\hline Tin, aluminium, and other metal items such as cans & $100-500$ years \\
\hline Plastic bags & one million years? \\
\hline Glass bottles & undetermined \\
\hline
\end{tabular}

\section{Hazardous Waste}

Industrial and hospital waste is considered hazardous as they may contain toxic substances. Certain types of household waste are also hazardous. Hazardous wastes could be highly toxic to humans, animals, and plants; are corrosive, highly inflammable, or explosive; and react when exposed to certain things e.g. gases. India generates around 7 million tonnes of hazardous wastes every year, most of which is concentrated in four states: Andhra Pradesh, Bihar, Uttar Pradesh, and Tamil Nadu.Household waste that can be categorized as hazardous waste include old batteries, shoe polish, paint tins, old medicines, and medicine bottles. Hospital waste contaminated by chemicals used in hospitals is considered hazardous. These chemicals include formaldehyde and phenols, which are used as disinfectants, and mercury, which is used in thermometers or equipment that measure blood pressure. Most hospitals in India do not have proper disposal facilities for these hazardous wastes.In the industrial sector, the major generators of hazardous waste are the metal, chemical, paper, pesticide, dye, refining, and rubber goods industries. Direct exposure to chemicals in hazardous waste such as mercury and cyanide can be fatal. 


\section{Hospital Waste}

Hospital waste is generated during the diagnosis, treatment, or immunization of human beings or animals or in research activities in these fields or in the production or testing of biologicals. It may include wastes like sharps, soiled waste, disposables, anatomical waste, cultures, discarded medicines, chemical wastes, etc. These are in the form of disposable syringes, swabs, bandages, body fluids, human excreta, etc. This waste is highly infectious and can be a serious threat to human health if not managed in a scientific and discriminate manner. It has been roughly estimated that of the $4 \mathrm{~kg}$ of waste generated in a hospital at least $1 \mathrm{~kg}$ would be infected.Surveys carried out by various agencies show that the health care establishments in India are not giving due attention to their waste management. After the notification of the Bio-medical Waste (Handling and Management) Rules, 1998, these establishments are slowly streamlining the process of waste segregation, collection, treatment, and disposal. Many of the larger hospitals have either installed the treatment facilities or are in the process of doing so.

\section{Municipal Solid Waste Generation Quantity In Indian Cities}

The six metro cities, Kolkata, Mumbai, Delhi, Chennai, Hyderabad and Bangalore together generate 48,000 TPD (17.5 million TPY) of MSW. Currently, India has 53 cities with populations greater than one million, generating $86,245 \mathrm{TPD}$ ( 31.5 million TPY), which is about $46 \%$ of the total MSW generated in urban India. The remaining 313 cities generate 15.7 million TPY (43,000 TPD), 23\% of the total urban MSW, only half of that generated by the 53 cities with million plus population. Urban India generates 188,500 tons per day (68.8 million tons per year) of municipal solid waste (MSW) at a per capita waste generation rate of 500 grams/person/day. The total waste generation figure is achieved by extrapolating the total tonnage of wastes documented for 366 cities. The below table 2 shows the municipal solid waste management in major cities in India.

Table-2, Municipal Solid Waste Generated In Major Cities Of India

\begin{tabular}{|c|c|c|}
\hline S.NO & CITY & MSWGENERATED(TPD) \\
\hline $\mathbf{1}$ & Greater Kolkata & $\mathbf{1 1 , 0 6 0}$ \\
\hline 3 & Greater Mumbai & 11,5588 \\
\hline 4 & Delhi & $\mathbf{6 , 4 0 4}$ \\
\hline 5 & Chennai & $\mathbf{5 , 1 5 4}$ \\
\hline & Greater Hyderabad & $\mathbf{3 , 5 0 1}$ \\
\hline
\end{tabular}

Source: Central Pollution Control Board

ULBs spend about $\$ 10-30$ (INR $500-1,500$ ) per ton on SWM. About $60-70 \%$ of this amount is spent on collection, $20-30 \%$ on transportation. No financial resources are allotted for scientific disposal of waste. Despite the fairly high expenditure, the present level of service in many urban areas is so low as to be a potential threat to the public health and environmentalquality. A guidance note titled "Municipal Solid Waste Management on a Regional Basis", by the Ministry of Urban Development (MOUD), Government of India (GOI) observes that "Compliance with the MSW Rules 2000 requires that appropriate systems and infrastructure facilities be put in place to undertake scientific collection, management, processing and disposal of MSW. However, authorities are unable to implement and sustain separate and independent projects to enable scientific collection, management, processing and disposal of MSW. This is mainly due to lack of financial and technical expertise and scarcity of resources, such as land and manpower."

Efforts towards proper SWM were made by urban local bodies (ULBs) equipped with financial and managerial capacity to improve waste management practices in response to MSW Rules 2000. Despite these efforts to manage wastes, more than $91 \%$ of MSW collected is still land filled or dumped on open lands and dumps, impacting public health, deteriorating quality of life and causing environmental pollution. It is estimated that about $2 \%$ of the uncollected wastes are burnt openly on the streets; and about $10 \%$ of the collected MSW is openly burnt in landfills or is caught in landfill fires. The MSW collection efficiency in major metro cities still ranges between $70-90 \%$ of waste generated, whereas smaller cities and towns collect less than $50 \%$ of waste generated.17 cities out of 59 surveyed by Central Pollution Control Board, CPCB have proposed new sites for landfills 24 cities (23.4 million TPY) use 34 landfills for dumping their waste, covering an area of 1,900 hectares. In the following table 3potrays area occupied by known landfills in India 
An Analytical Study On Problems And Policies Of Solid Waste Management In India ....

Table-3, Area Occupied By Known Landfills In India;

\begin{tabular}{|c|c|c|}
\hline NAME OF CITY & NO. OF LANDFILL & SITES AREA OF LANDFILL (HA) \\
\hline Chennai & 2 & 465.5 \\
\hline Coimbatore & 2 & 292 \\
\hline Surat & 1 & 200 \\
\hline Greater Mumbai & 3 & 140 \\
\hline Greater Hyderabad & 1 & 121.5 \\
\hline Ahmadabad & 1 & 84 \\
\hline Delhi & 3 & 66.4 \\
\hline Jabalpur & 1 & 60.7 \\
\hline Indore & 1 & 59.5 \\
\hline Madurai & 1 & 48.6 \\
\hline Greater Bangalore & 2 & 240.7 \\
\hline Greater Visakhapatnam & 1 & 40.5 \\
\hline Ludhiana & 1 & 40.4 \\
\hline Nashik & 1 & 34.4 \\
\hline Jaipur & 3 & 31.4 \\
\hline Srinagar & 1 & 30.4 \\
\hline Kanpur & 1 & 27 \\
\hline Kolkata & 1 & 24.7 \\
\hline Chandigarh & 1 & 18 \\
\hline Ranchi & 1 & 15 \\
\hline Raipur & 1 & 14.6 \\
\hline Meerut & 2 & 14.2 \\
\hline Guwahati & 1 & 13.2 \\
\hline Thiruvananthapuram & 1 & 12.15 \\
\hline Total & 85 & 1894 \\
\hline
\end{tabular}

\section{SOURCE: CPCB}

\section{Impacts of Improper Waste Management}

Improper solid waste management deteriorates public health, degrades quality of life, and pollutes local air, water and land resources. It also causes global warming and climate change and impacts the entire planet. Improper waste management is also identified as a cause of 22 human diseases and results in numerous premature deaths every year. Indiscriminate dumping of wastes and leach ate from landfills contaminates surface and groundwater supplies and the surrounding land resources. It also clogs sewers and drains and leads to floods. Mumbai experienced a flood in 2006 which was partly due to clogged sewers. Insect and rodent vectors are attracted to MSW and can spread diseases such as cholera, dengue fever and plague. Using water polluted by solid waste for bathing, food irrigation, and as drinking water can also expose individuals to disease organisms and other contaminants.

Open burning of MSW on streets and at landfills, along with landfill fires emit 22,000 tons of pollutants into the lower atmosphere of Mumbai city, every year. The pollutants identified in Mumbai due to uncontrolled burning of wastes are carbon monoxide (CO), carcinogenic hydro carbons (HC) (includes dioxins 
and furans), particulate matter (PM), nitrogen oxides (NOx) and sulfur dioxide (SO2). MSW dumped in landfills also generates green house gases like...methane, which has 21 times more global warming potential than carbon dioxide. Improper SWM contributes to $6 \%$ of India's methane emissions and is the third largest emitter of methane in India. This is much higher than the global average of 3\% methane emissions from solid waste. It currently produces 16 million tons of $\mathrm{CO} 2$ equivalents per year and this number is expected to rise to 20 million tones of $\mathrm{CO} 2$ equivalent by 2020. The world is moving towards calling wastes as "resources". Due to the inability to manage these resources in the next decade, India will landfill 6.7 million tons of recyclables (or secondary raw materials); 9.6 million tons of compost (or organic fertilizer); and resources equivalent to 57.2 million

barrels

of

\section{Population And Municipal Solid Waste Generation In India}

India is the second most populous nation on the planet. The Census of 2011 estimates a population of 1.21 billion which is $17.66 \%$ of the world population. It is as much as the combined population of USA, Indonesia, Brazil, Pakistan, Bangladesh and Japan. The population of Uttar Pradesh, one among 28 Indian states is greater than that of Brazil, the fifth most populous nation in the world. India's urban population was 285 million in 2001 and increased to 377 million in 2011. Indian urban population is greater than the total population of USA (308.7 million), the third most populousnation.366 cities which represent $70 \%$ of India's urban population and generate 130,000 tons per day (TPD) or 47.2 million tons per year (TPY) at a per capita waste generation rate of 500 grams/day. This implies the total MSW generated by urban India could be as much as 188,500 TPD or 68.8 million TPY. This number matches the projection (65 million TPY in 2010) by Sunil Kumar, et al. (17). Therefore, this report assumes that the quantum of waste generated by urban India to be 68.8 million TPY. The general consensus on amount of waste generated by urban India is 50 million TPY, which is very low in comparison to the current findings.

Indian population increased by more than 181 million during 2001 - 2011, a $17.64 \%$ increase in population, since 2001. Even though this was the sharpest decline in population growth rate registered postIndependence the absolute addition during 2001-2011 is almost as much as the population of Brazil, the fifth most populous country in the world. It is clear that the scale of populations dealt with in case of India and China are entirely different from any other country in the world. Indian urban population increased by $31.8 \%$ during $2001-2011$, which implies an annual growth rate of $2.8 \%$ during this period.

\section{Impact Of Population Growth On Municipal Solid Waste (Msw) Generation}

Population growth and rapid urbanization means bigger and denser cities and increased MSW generation in each city. The data compiled by central pollution control board report indicates that 366 cities in India were generating 31.6 million tons of waste in 2001 and are currently generating 47.3 million tons, a 50\% increase in one decade. It is estimated that these 366 cities will generate 161 million tons of MSW in 2041, a five-fold increase in four decades. At this rate the total urban MSW generated in 2041 would be 230 million TPY (630,000 TPD).MSW Rules 2000 mandate "landfills should always be located away from habitation clusters and other places of social, economic or environmental importance", which implies lands outside the city. Therefore, increase in MSW will have significant impacts in terms of land required for disposing the waste as it gets more difficult to site landfills. Farther the landfill gets from the point of waste generation (city), greater will be the waste transportation cost.

Rapid industrialization and population explosion in India has led to the migration of people from villages to cities, which generate thousands of tons of MSW daily. The MSW amount is expected to increase Significantly in the near future as the country strives to attain an industrialized nation status by the year 2020 (Sharmaand Shah, 2005; CPCB, 2004; Shekdar et al., 1992). Poor collection and inadequate transportation are responsible for the accumulation of MSW at every nook and corner. The management of MSW is going through a critical phase, due to the unavailability of suitable facilities to treat and dispose of the larger amount of MSW generated daily in metropolitan cities. Unscientific disposal causes an adverse impact on all components of the environment and human health (Rathi, 2006; Sharholy et al., 2005; Ray et al., 2005; Jha et al., 2003; Kansal, 2002; Kansal et al., 1998; Singh and Singh, 1998; Gupta etal.,

A 1998 study by TERI (The Energy Resources Institute, earlier Tata Energy Research Institute) titled 'Solid Waste Management in India: options and opportunities' calculated the amount of land that was occupied by waste disposed post independence, until 1997. The study compared the land occupied in multiples of the size of a football field and arrived at 71,000 football fields of solid waste, stacked 9 meters high. Based on a business as usual (BAU) scenario of $91 \%$ land filling, the study estimates that the waste generated by 2001 would have occupied 240 sq.km or an area half the size of Mumbai; waste generated by 2011 would have occupied 380 sq.km or about 220,000 football fields or $90 \%$ of Chennai, the fourth biggest Indian city area-wise; waste generated by 2021 would need 590 sq.km which is greater than the area of Hyderabad (583 sq.km), the largest 
Indian city, area-wise. The Position Paper on The Solid Waste Management Sector in India, published by Ministry of Finance in 2009, estimates a requirement of more than $1400 \mathrm{sq} . \mathrm{km}$ of land for solid waste disposal by the end of 2047 if MSW is not properly handled and is equal to the area of Hyderabad, Mumbai and Chennai together.

\section{Methods Of Solid Waste Management}

Recycling, Composting, and the Hierarchy of Sustainable Waste Management

1TheHierarchy

2.MaterialRecoveryRecycling

3.MaterialRecovery:AerobicComposting

Reduce, Reuse, Recycle Methods of waste reduction, waste reuse and recycling are the preferred options when managing waste. There are many environmental benefits that can be derived from the use of these methods. They reduce or prevent green house gas emissions, reduce the release of pollutants, conserve resources, save energy and reduce the demand for waste treatment technology and landfill space. Therefore it is advisable that these methods be adopted and incorporated as part of the waste management plan.

\section{Thehierarchy}

The Hierarchy of Sustainable Waste Management developed by the Earth Engineering Center at Columbia University is widely used as a reference to sustainable solid waste management and disposal. This study is presented in reference to this hierarchy. "Unsanitary Land filling and Open Burning" has been added to the original hierarchy of waste management which ends with sanitary landfills (SLFs). Unsanitary landfilling and open burning will represent the indiscriminate dumping and burning of MSW and represents the general situation of SWM in India and other developing countries.

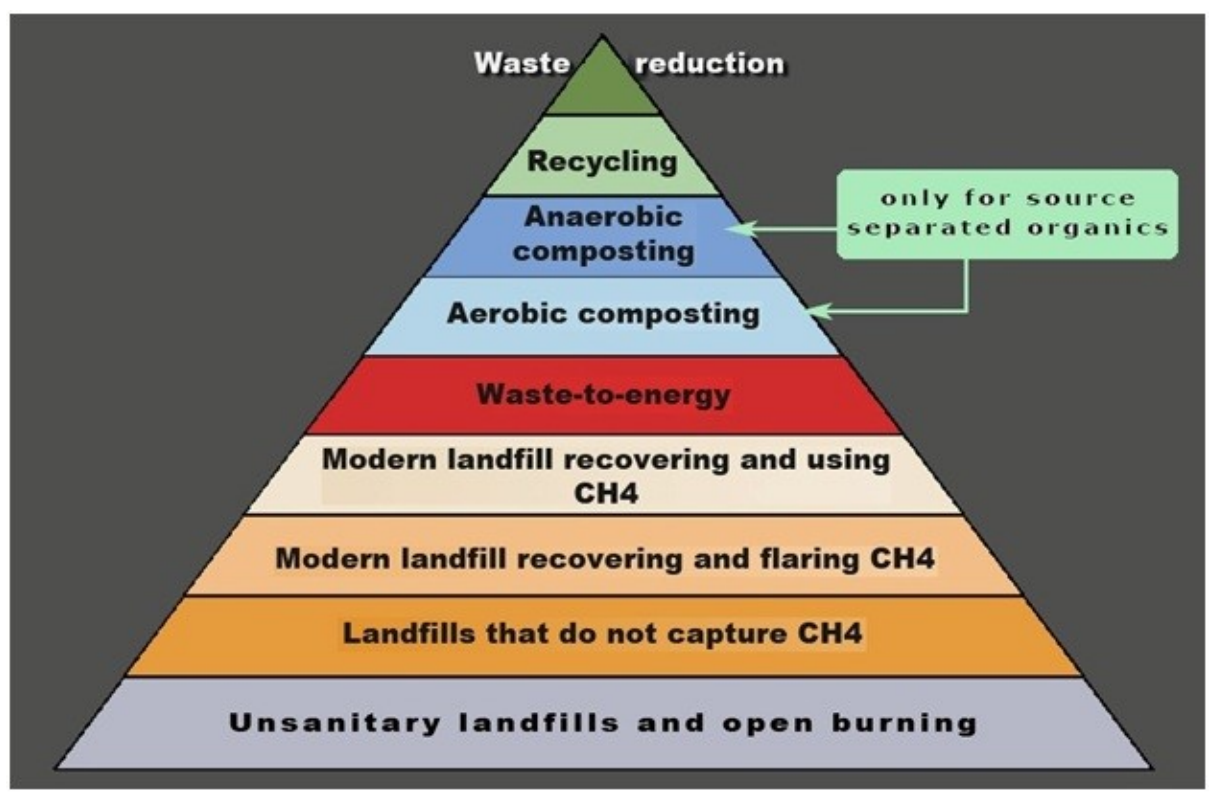

The Hierarchy of Sustainable Waste Management for India and Other Developing Nations

The hierarchy of waste management recognizes that reducing the use of materials and reusing them to be the most environmental friendly. Source reduction begins with reducing the amount of waste generated and reusing materials to prevent them from entering the waste stream (15). Thus, waste is notgenerateduntiltheendof "reuse"phase. Once the waste is generated, it needs to be collected. Material recovery from waste in the form of recycling and composting is recognized to be the most effective way of handling wastes. Due to technical and economic limitations of recycling; product design; inadequate source separation; and lack of sufficient markets that can use all sorted materials, most of the MSW generated in India ends up in landfills. Local authorities should start working with their partners to promote source separation. While this is being achieved and recycling is increased, provisions should be made to handle the non-recyclable wastes that are and will be generated A sustainable solution to handle non-recyclable waste is energy recovery. Energy recovery from wastes falls below material recovery. Landfilling of MSW is equivalent to burying natural resources which could be used as secondary raw materials or as sources of energy. However, in the present society, landfills are required as a small fraction of wastes will have to be landfilled. However, unsanitary landfilling or open dumping of wastes is not considered as an option to handle MSW and is not at all recommended. 


\section{Material Recovery: Recycling}

Reducing and reusing are the most effective ways to prevent generation of wastes. Once the wastes are generated and collected, the best alternative to handle them would be recycling where the materials generally undergo a chemical transformation. Sometimes, reusing can also happen after collection, in cases where informal traders collect materials of no use from households, reshape or repair them and sell in second-hand markets. Unlike reusing a used material, recycling involves using the waste as raw material to make new products. Recycling thus offsets the use of virgin raw material

It is known that as much as $95 \%$ of a product's environmental impact occurs before its discarded, most of it during its manufacturing and extraction of virgin raw materials. Thus, recycling is pivotal in reducing the overall life cycle impacts of a material on environment and public health. Recycling however requires a separated stream of waste, whether source separated or separated later on (after collection).Due to the limitations for source separation (See Section 5.6), wastes are collected in a mixed form which is referred to as municipal solid waste (MSW). Once the wastes are mixed it becomes difficult to separate them. Recyclables can still be separated manually to some extent. Such separation and sale of recyclables from mixed wastes provides livelihood to marginalized urban populations in low and middle income countries. High income countries use machines to do the same but they would need the recyclables to be collected as a separate dry stream without mixing with organic food wastes. The separated stocks of paper, plastic, glass and metal can then be recycled. A hundred percent separation of these materials from MSW is highly energy and time intensive and is generally not carried out. Therefore, mixing of waste will always result in a fraction of residues, which can neither be recycled nor composted and needs to be combusted in RDF or WTE plants to avoid landfilling, and generate energy.

\section{Material Recovery: Aerobic Composting}

Similar to the recycling of inorganic materials, source separated organic wastes can be composted and the compost obtained can be used as an organic fertilizer on agricultural fields. Organic compost is rich in plant macro nutrients like Nitrogen, Phosphorous and Potassium, and other essential micro nutrients. Advantages of using organic manure in agriculture are well established and are a part of public knowledge. United Nations Environment Program (UNEP) defines composting as the biological decomposition of biodegradable solid waste under predominantly aerobic conditions to a state that is sufficiently stable for nuisance-free storage and handling and is satisfactorily matured for safe use in agriculture. Composting can also be defined as human intervention into the natural process of decomposition as noted by Cornell Waste Management Institute. The biological decomposition accomplished by microbes during the process involves oxidation of carbon present in the organic waste. Energy released during oxidation is the cause for rise in temperatures in windrows during composting. Due to this energy loss, aerobic composting falls below anaerobic composting on the hierarchy of waste management. Anaerobic composting recovers both energy and compost. Life cycle impacts of extracting virgin raw materials and manufacturing make material recovery options like recycling and composting the most environment friendly methods to handle waste. They are positioned higher on the hierarchy compared to other beneficial waste handling options like energy recovery. However, quality of the compost product depends upon the quality of input waste. Composting mixed wastes results in low quality compost, which is less beneficial and has the potential to introduce heavy metals into human food chain.

Aerobic composting of mixed waste results in a compost contaminated by organic and inorganic materials, mainly heavy metals. Contamination of MSW compost by heavy metals can cause harm to public health and environment and is the major concern leading to its restricted agricultural use (22). Mixed waste composting is therefore not an option for sustainable waste management, but this issue is not a part of public knowledge. Mixed waste composting is widely practiced and is considered better (if not best) (8) in countries like India where more than $91 \%$ of MSW is landfilled and there are no other alternatives. It is considered better probably because public health and environmental impacts of unsanitary landfilling are more firmly established by research than those impacts due to heavy metal contamination of MSW compost.

\section{Solid Waste Management In Bruhat Bangalore Mahanagara Palike}

The total geographical area of Bangalore is $800 \mathrm{sq} \mathrm{km}$ and total Population (2008) has been 78 lakhs.,Householdsare 25 lakhs,Commercial Properties are 3.5 lakhs. The No of Zones are 8, No of Wards are 198for BBM. An Estimated MSW generation Projection for each year from all sources for BBMP zones is 3000 tpd and per capita waste is 350 grams per day (gmpd) (domestic waste). Households contribute to 54\% percent of the total waste; Markets \&function halls contribute to $20 \%$ and, Commercial establishment \&institutions contribute to $17 \%$ and, others $9 \%$, Segregation of waste at source $10 \%$ 


\section{Composition of Municipal Solid Waste:}

\section{Physical composition of MSW (\%)}

\begin{tabular}{|l|l|l|}
\hline 1 & vegetable & 0.30 \\
\hline 2 & paper & 0.09 \\
\hline 3 & plastic & 0.12 \\
\hline 4 & Cardboard & 0.04 \\
\hline 5 & Textiles & 0.04 \\
\hline 6 & Grass/Leaves/Wood & 0.06 \\
\hline 7 & Leather & 0.00 \\
\hline 8 & Battery & 0.02 \\
\hline 9 & Electronic items & 0.01 \\
\hline 10 & Metal & 0.23 \\
\hline 11 & Organic & 0.03 \\
\hline 12 & Glass & 0.05 \\
\hline 13 & Debris & 0.02 \\
\hline 14 & Biomedical & 0.02 \\
\hline
\end{tabular}

(Chemical composition of MSW (\%)

\begin{tabular}{|l|l|l|l|}
\hline Sl.no. & Constituent/property & Minimum & Maximum \\
\hline $\mathbf{1}$ & $\mathbf{C}$ & $\mathbf{1 3 . 0 0}$ & $\mathbf{4 2 . 6 0}$ \\
\hline 2 & $\mathrm{~N}$ & 0.28 & 1.23 \\
\hline 3 & $\mathrm{P} 2 \mathrm{O} 5$ & 0.46 & 0.92 \\
\hline 4 & $\mathrm{~K} 2 \mathrm{O}$ & 0.45 & 1.07 \\
\hline 5 & Moisture\% & 13.80 & 40.90 \\
\hline
\end{tabular}

source:SWM Master plan 2008)

As per the Municipal Solid Waste Management rules 2000 BBMP is responsible for taking the waste management as per the stipulation. For Administrative purpose BBMP is divided into 8 zones, 3 zones in old area (core area) \& 5 zones in new area (adjacent 7 CMC's \& one TMC).

-About $70 \%$ of the MSW (Municipal Solid waste) activity starting from primary collection to disposal has been outsourced \& $30 \%$ is managed by BBMP

- There are about 4300 Poura karmikas (Sweepers) of BBMP \& 10000 Pourakarmikas (Sweepers) from contractor who performs Door toDoor collection \& sweeping activities.

- In some of the area in the new zones the Door to Door collection activity is entrusted to Self Help Groups (SHG's). Which are basically below poverty women's groups

- In some of the residential areas the Residential Welfare Associations (RWA's) are involved in Door to Door collection \& decentralization of composting the waste

\section{Primary Collection (Door to Door collection)}

The primary collection is performed using pushcarts \& auto tippers

- There are around 11000 pushcarts \& 650 auto tippers for Door to Doorcollection of waste.

- Waste is collected in the unsegregated form as segregation is notpracticed at source.

\section{Secondary collection and Transportation}

There are about $600 \mathrm{MSW}$ transportation vehicles includingCompactors, Tipper Lorries, Dumper placers \& Mechanical Sweepersboth BBMP and contractors.

The waste collected from the households is brought to a common pointie., secondary locations from where the waste is shifted to thetreatment sites through compactors \& tipper lorries.

- Segregation at source $\&$ the secondary storage is not happening henceunsegregated waste reaches the processing plants.

Street Sweeping activity

- Street sweeping is performed both manually \& mechanically. In someof the highly commercial activity areas sweeping is done at night $\&$ inthe VIP areas the sweeping is done mechanically. The street sweepingwaste is carried along with the primary collection waste to the land fill sites.

Decentralized processing plants

Some of the areas where RWA's are performing Door to Door collection, the waste is segregated at source \& the organic waste is composted in the community in a small scale.

BBMP has setup a 15 ton capacity decentralized plant to process organic waste as well as recycle the plastic, metal etc

BBMP has established an decentralizes one ton capacity aerobic composting unit at Malleshwaram market

(West Zone) using organic waste convertor.

Dry waste collection centers

- Dry waste collection centers has been set up for recycling the dry materials like plastic, paper, glass, metals etc Processing \& Disposal sites 
In order to comply with MSW rules, The BBMP has setup processing \&Disposal facilities on PPP model. Following are the processing $\&$ disposing facilities.

\begin{tabular}{|l|l|l|l|}
\hline Sl.no & Name of the project & Capacity of plant & Technology adopted \\
\hline 1 & M/s Ramky & 1600 MTPD & $\begin{array}{l}\text { Aerobic composting \&scientific } \\
\text { landfill }\end{array}$ \\
\hline 2 & M/S G.R.R.L & $1000 \mathrm{MTPD}$ & $\begin{array}{l}\text { Waste to energy(presently } \\
\text { composting \& land filling the } \\
\text { inert\&combustible.material } \\
\text { stored for RDF) }\end{array}$ \\
\hline 3 & M/s Terrafirma & $1000 \mathrm{MTPD}$ & $\begin{array}{l}\text { Integrated system where } \\
\text { composting, vermin } \\
\text { composting,biomethanization is } \\
\text { followed }\end{array}$ \\
\hline 4 & $\begin{array}{l}\text { M/s Organic Waste India pvt } \\
\text { Itd (yet to } \\
\text { start) }\end{array}$ & $\begin{array}{l}1000 \\
\text { MTPD }\end{array}$ & $\begin{array}{l}\text { Integrated system } \\
\text { (yet to commission) }\end{array}$ \\
\hline
\end{tabular}

_ The combination of technologies for processing of MSW attempted for sustenance \& viability.

- Generally around 30 to 40 percent of inert rejects which includes recyclables are going to the scientific landfill.

Attempt is being made to utilize all the recyclables

Small quantity of Waste Plastic are segregated and used in the construction of pavement roads. $8 \%$ of Poly $\bar{b}$ lend is mixed in the asphalt

_ It is seen there is possibility of converting the plastics into diesel by following depolymerization technology which is yet to be implemented in large scale.

Our aim is to adopt zero waste management or reduced the quantity of inert that goes to landfills by less than $10 \%$ by recycling other inert wherever possible.

\section{Vehicle Tracking System using GPS}

- To bring in accountability for the distance traveled by the vehiclesGPS/GPRS Based Tracking system is implemented.

- About 350 vehicles are fitted with the GPSCCTV and Hand held device

- CCTV cameras have been installed at all the processing sites at the entry and exit points to view the vehicles reached.

- Also a ticketing system using Hand Held Device, which collect the dataand send it to the central server for monitoring and analysis.

- The entire truck numbers and operation schedule is automatically downloaded to the Hand Held device through GPRS

E-waste

_ Bangalore being the Silicon Valley huge quantity of e-waste is generated.

_ Recyclers identified by the KSPCB are managing the e-waste at large IT companies.

_ today the e-waste is one of the rapidly growing environmental problems

- with extensive use of computers and other electronic equipments coupled with increasing discarding habits, rapid technological change, there is a significant increase in e-waste generation at the household level and public sectors which has to be addressed.

\section{Conclusions}

The existing solid waste system in Bangalore city is effective in carrying out the functions of primary collection and transport. However, there has been a significant problem in realizing the large sustainability goals due to the systems heavily relying on centralized waste treatment and disposal system. In fact the current payment mode is conducive to showing at least 30\% land filling fraction in the USW collected. This is not conducive to sustainability as there is no reward for complete recovery of recyclables and fermentable. On the other hand, with some modifications in the way waste is collected, it is possible to run decentralized, ward-wise or smaller systems that are more sustainable (economically, environmentally and socially), and overcome some of the lacunae faced in the centralized systems. Decentralized systems of the future can provide greater sustainability but will require a higher level of waste generation and handling discipline. Finally, concludes that the problem of solid waste needs some holistic approaches such as reuse of solid waste to produce energy and biomennures. 


\section{References}

[1]. Chanakya H. N. and Sharatchandra H. C. 2005. GHG footprint of a developing country city - Bangalore. ASTRA technical report, CST. Bangalore.

[2]. Chanakya H. N., Ramachandra T. V., Vijayachamundeeswari. 2007. Environ Monit Assess. DOI

[3]. 10.1007/s10661-007-9712-4.

[4]. Lakshmikantha H. 2006. Report on waste dump sites around Bangalore. Waste Management. 26. 640-650.

[5]. Morgenstern Richard D. 1991. Towards a Comprehensive Approach to Global Climate Change Mitigation.

[6]. The American Economic Review. 81(2). 1991. 140-145

[7]. Rajabapaiah P. 1988. Energy from Bangalore garbage- A preliminary study. ASTRA technical report, CST. Bangalore.

[8]. TIDE (Technology Informatics Design Endeavour). 2000. Energy recovery from municipal solid wastes in around Bangalore. Technical report. Bangalore.

[9]. Van Beukering Pieter. 1994. An economic analysis of different types of formal and informal entrepreneurs, recovering urban solid waste in Bangalore (India)

[10]. Sunil Kumar ,J.K.2008,A.N.Vaidya,Tapan Chakravarthy,Sukumar Devotta,A,B,Akolkar;Assessment of Municipal Waste Management in Metro cities, state capitals,class1 cities and class II towns in India;An insight.

[11]. Kant,Ravi,Managing Director,Ramky Environment Engineers Ltd.

[12]. Ministry of Urban Development, Government of India,Guidance note;Municipal solid Watse Management on a Regional Basis,online.

[13]. Annepu, Ranjith Kharvel. Sustainable Solid Waste Management in India. January 10, 2012. 